\title{
Intermediate Products and the Last Stages of Carbohydrate Breakdown in the Metabolism of Muscle and in Alcoholic Fermentation*
}

\section{By Dr. Otto Meyerhof}

$\mathrm{T}$ HE esterification of the phosphates may be regarded as the first step of the anærobic carbohydrate breakdown, not only in lactic acid formation in muscle, but also in alcoholic fermentation. Whereas our earlier studies were principally concerned with the conditions under which this esterification occurs and the quantitative relations connected with it, the stages following esterification lead to the well-known end products, on one hand lactic acid, and on the other hand alcohol and carbon dioxide.

It has gradually become more certain that the hexose $d i$-phosphoric acid, isolated by Harden and Young from yeast-press juice, occurs neither in living yeast nor in other intact cells or tissues. A hexose mono-phosphoric acid possessing the chemical properties of the ester isolated in 1914 by Harden and Robison is always found; and may be termed the 'Robison' ester. This is particularly true for the hexose phosphoric acid of muscle, discovered by Embden and termed by him 'lactacidogen'. 'This is, for all practical purposes, identical with the Robison ester. Lohmann and Meyerhof showed, as Robison had already suspected, that this ester is not a uniform single substance, but a mixture, consisting of about three quarters aldose mono-phosphoric acid and one quarter ketose mono-phosphoric acid. This is worthy of notice in view of the relations existing between these esters and the hexose di-phosphoric acid, for the Harden-Young ester is a fructose di-phosphoric acid, while the mono-ester obtained by Neuberg by splitting off a phosphoric acid group from the di-ester is also a fructose ester.

Dr. Lohmann succeeded not long ago in solving the puzzle. The Robison and the Embden esters are nothing other than an equilibrium mixture of both components. This equilibrium mixture is formed in a few seconds from either the pure glucose or fructose ester in the presence of an enzyme found in all cells. Next, the enzymatic conversion of the Harden-Young ester into a mono-ester produced in no case the Neuberg ketose ester, obtained by acid hydrolysis, but always the Robison-Embden ester. It was possible to split off one phosphoric acid group by using dialysed aqueous muscle extract. The organic component of the co-enzyme, adenylpyrophosphoric acid, was thus dialysed away. Magnesium ion, the inorganic component, was then added. Muscle extract has no effect at all upon hexose di-phosphoric acid in the absence of magnesium and adenylpyrophosphate. With magnesium alone, however, one phosphoric acid group is split off.

* Iecture delivered in the Biuchemical Laboratory, Cambridge, in July 1833.
The formation of the Robison ester under this condition may be explained by the following observation: if, instead of hexose di-phosphoric acid, one takes the Neuberg ester and adds it to muscle extract, the Robison-Embden ester appears after a few scconds. This last conversion takes place not only in magnesium-free extracts, but also in very dilute, thoroughly dialysed enzyme solutions of any origin. In every case, this conversion leads not to a pure glucose monophosphoric acid, but to an equilibrium mixture consisting of 70 per cent aldose phosphoric acid and 30 per cent unchanged fructose phosphoric acid. It can be shown that this is a true equilibrium by beginning with a pure or nearly pure glucosemono-phosphoric acid, obtained either according to Lohmann by a partial acid hydrolysis of the Embden ester, or even better by using the method of Robison and Morgan. A part of this glucose

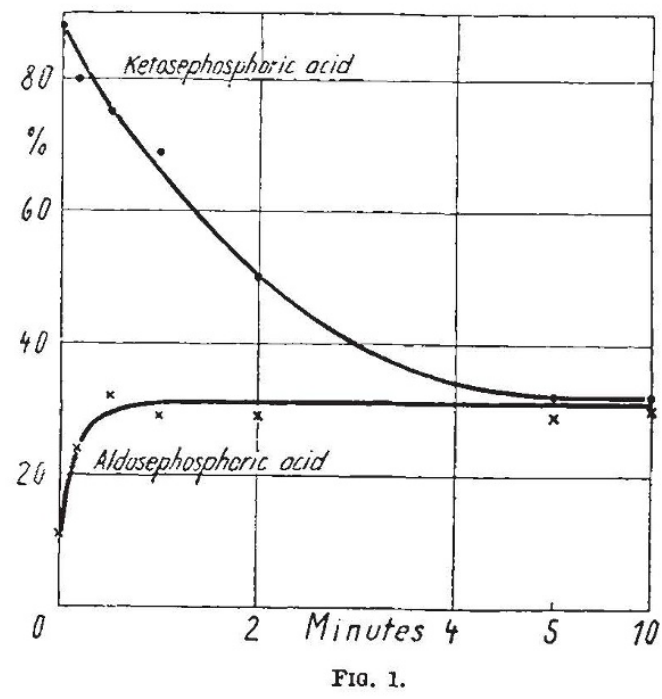

mono-phosphoric acid is converted into fructose phosphoric acid. The reaction comes to equilibrium again, when 30 per cent of the fructose component has been formed (see Fig. 1). With this, one of the difficulties which spoke against the mutual conversion of the Harden-Young ester and the Robison-Embden ester was removed. Such conversions in both directions play indeed an important part in carbohydrate metabolism.

'The next question is, what is the next intermediary step in carbohydrate breakdown? An excellent technical aid in the study of this problem is the addition of sodium fluoride to the enzyme mixture. Embden observed many years ago that addition of sodium fluoride inhibited the lactic acid production of muscle, but that at the same time the hexose phosphoric acid increased. The 
isolation of the Harden-Young hexose di-phosphoric acid under these conditions led to the suggestion that this acid was perhaps the preformed precursor of lactic acid. This conception must be limited in two ways, first, that the diphosphate is not preformed, but results from conversion of other esters. This conversion is due to the change in the course of the reaction resulting from the mincing of the tissue and the influence of the fluoride ion. Secondly, only a part of the ester accumulated here is the true Harden-Young ester. Lohmann showed in 1930 that a considerable same time that the phosphoglyceric acid is transformed into pyruvic acid by minced muscle as shown in section $\mathrm{C}$ of Table 1 . Embden therefore suspected that $\alpha$-glycero-phosphoric acid appeared at the same time as a reduction product. He did not succeed, however, in isolating this substance. He set up a scheme for the breakdown of hexose di-phosphoric acid to lactic acid, shown in Table 1 , which our investigations have shown to be essentially correct.

At the time Embden published his important results we had already succeeded in our laboratory in obtaining $\alpha$-glycero-phosphoric acid, not only from the Lohmann ester but also as a dismutation product by fixing the pyruvic acid with sulphite. The formation of pyruvic acid under anærobic conditions in minced muscle has been described by various authors. part, and under some conditions even the whole, of the ester present is not identical with the Harden-Young ester; although the elementary constitution is the same. He called it at that time the 'unhydrolysable' ester, because normal hydrochloric acid at $100^{\circ}$ splits off a phosphoric acid group very much more slowly than in the case of the Harden-Young ester. This is clearly seen from the curves published by Lohmann ${ }^{1}$. The hydrolysis curves show the ester transformation by the fluoridecontaining muscle extracts after varying length of time. As this 'Isohmann' ester is formed not only in the presence of glycogen, but also from the

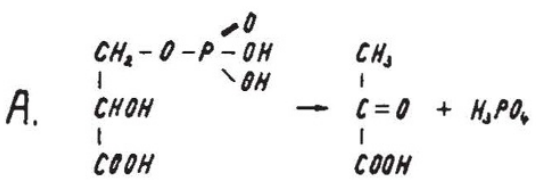

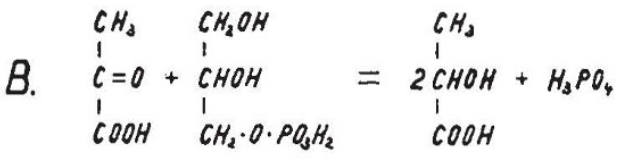

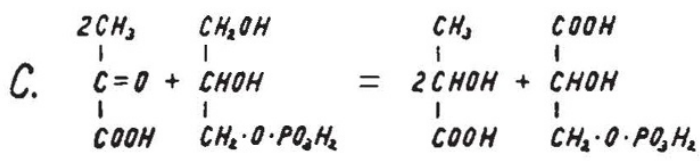

$$
\begin{aligned}
& \text { FIG. } 2 .
\end{aligned}
$$

Harden-Young ester, without the splitting off of phosphoric acid, it must be a rearrangement product. This rearrangement product was converted enzymatically into lactic acid. More details concerning this ester were not found at the time although one suspected it of being a hexose diphosphoric acid.

At the beginning of this year, Embden reported the important observation that under the conditions defined by Lohmann, glyceric-acid-monophosphoric acid (abbreviated 'phospho-glyceric acid') could be identified. He discovered at the have occupied themselves with this problem.

Hahn concluded from his experiments that a quarter of the lactic acid accumulating anærobically in muscle was converted into pyruvic acid, the oxidation being accomplished by preformed hydrogen acceptors present in the tissue. That this was impossible could be seen from the experiments of Case, to whom we owe an accurate and simple method for quantitative determination of small amounts of pyruvic acid. He found that in an aqueous muscle extract addition of starch and sulphite led to a large increase in the pyruvic acid, whereas addition of sulphite and lactate led only to a very small increase. The pyruvic acid must therefore originate from the carbohydrate, the quantity found being greatly increased by the sulphite used to fix the acid.

In our own work, the quantitative relationships in this formation of pyruvic acid and the origin of the oxygen necessary under the anærobic conditions were thoroughly investigated. The assumed conversion of a quarter of the lactic acid formed under anærobic conditions in muscle tissue into pyruvic acid was not in agreement with former observations of mine showing the very close correspondence of carbohydrate disappearance and lactic acid formation. However, upon repeating the experiments under the same conditions, pyruvic acid was found, but only in a quantity of $3-5$ per cent of the lactic acid formed at the same time.

The earlier failure to notice this small quantity of pyruvic acid and the consequent maintenance of an approximate equality between carbohydrate disappearance and lactic acid formation are not difficult to understand. The pyruvic acid yield increases, however, when one minces the muscle finer, or adds sulphite as a fixative, or when glycogen, or still better, hexose di-phosphoric acid is added in excess. By using all these together the yield of pyruvic acid can be increased to 30 per cent of the lactic acid formed at the same time. In muscle extract there can even be obtained 
considerably more pyruvic than lactic acid. This could also be concluded from certain experiments of Case. We came another step further, however, in the search for the source of the oxygen necessary under anærobic conditions. As already mentioned, I found, working with Kiessling, $\alpha$-glycerophosphoric acid as a dismutation product.

Embden had already observed that simultaneous addition of phosphoglyceric acid and glycero. phosphoric acid to muscle tissue caused an inereased formation of lactic acid. If then the Embden scheme was correct, neither addition of pyruvic acid alone, nor of $\alpha$-glycero-phosphoric acid alone to carbohydrate-free muscle extract should lead to lactic acid production. On the other hand, addition of both at the same time should lead to the production of lactic acid, whereby twice as much lactic acid should be formed as pyruvic acid disappears. This is actually the case. The phosphate group split from glycero-phosphoric acid and the glycerol group disappears in exactly the quantity necessary to account for half the lactic acid formed. This is equation B shown in Fig. 2.

The $\alpha$-glycero-phosphoric acid isolated from the muscle is the $l$-component. This compound, as was known from former studies of the glycero-phosphoric acids, shows no measurable rotation. When one investigates, however, the dimethylester of the di-methyl ether, which we prepared according to Karrer's directions, a specific rotation $[\alpha]_{D}^{20^{\circ}}$ of $-4 \cdot 5^{\circ}$ is found. Only this $l$-acid, and not the optical antipode reacts with pyruvic acid to form lactic acid.

Fig. 3 shows the time course of the formation of lactic acid in muscle extract containing an excess of pyruvic acid, when known quantities of the natural or synthetic $\alpha$-glycero-phosphoric acid are present. The broken lines show the lactic acid formation when the natural $l$-product isolated from the muscle was used. The lower curve shows the experiments when a quantity of acid corresponding to $5.9 \mathrm{mgm}$. of glycerol was used. The other curve corresponds to $11.9 \mathrm{mgm}$. glycerol per 10 c.c. extract. For the other experiments, shown by the solid lines, a double quantity of the racemic acid was used, for the lower corresponding to $11.7 \mathrm{mgm}$. for the upper to $24.0 \mathrm{mgm}$. glycerol. If we examine the horizontal portions of the curve where the lactic acid production has reached a constant value, we see that, in comparison to the control, for $5.9 \mathrm{mgm}$. glycerol $12 \mathrm{mgm}$. of lactic acid have been formed and for $11.9 \mathrm{mgm}$. glycerol $24.0 \mathrm{mgm}$. lactic acid; that is, each time two molecules of lactic acid for one molecule of glycerol ; exactly as in the equation given. With the synthetic compound, however, only as much lactic acid is formed as there is glycero-phosphoric acid present. One may also show directly, that only half the glycero-phosphoric acid has reacted, from the determinations of the phosphate split off.

The given equation checks exactly, but is only a balance equation. In the scherne of Embden, pyruvic acid and glycero-phosphoric acid do not react directly to form two molecules of lactic acid, but instead form lactic acid and a triose phosphoric acid, the latter then rearranging to phosphoglyceric acid and glycero-phosphoric acid. The resulting phosphoglyceric acid then yields pyruvic acid, which reacts again with glycero-phosphoric acid until the whole has been converted into lactic acid. That this is the case is shown by the action of fluoride. Sodium fluoride inhibits the formation of lactic acid from carbohydrates. Now it can be seen that the effect is due to the inhibition of one partial reaction, namely the splitting off of phosphoric acid from the phosphoglyceric acid. The other links in the chain of reactions are not influenced by the fluoride ion. If, therefore, we add excess pyruvic acid and $\alpha$-glycero-phosphoric acid to a muscle extract and add enough fluoride to stop completely the anærobic breakdown of glycogen and hexose di-phosphate, we obtain exactly as much lactic acid as without fluoride. But now the disappearance of pyruvic acid and the formation of lactic acid are exactly equivalent. This is expressed in equation $\mathrm{C}$ in Fig. 2.

In this case no phosphate has been split off and the glycero-phosphoric acid in the presence of an

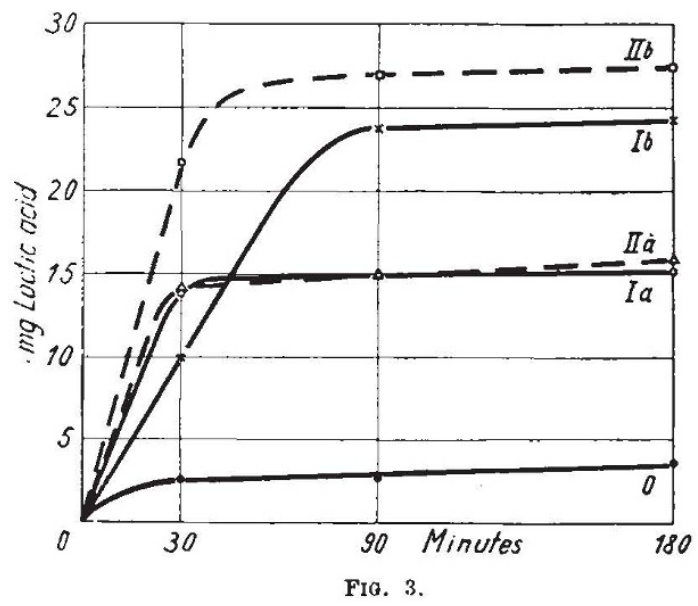

excess of pyruvic acid is completely converted into phosphoglyceric acid. This course of the reaction can only then take place, if the pyruvic acid and the glycero-phosphoric acid do not react directly to form two molecules of lactic acid, but if one half becomes triose phosphate which then rearranges. The glycero-phosphoric acid thus formed can again react with pyruvic acid but the phosphate group of phosphoglyceric acid is not split off. That proceeds until all the glycero. phosphoric acid is oxidised to phosphoglyceric acid. Sodium fluoride acts therefore as a trap for the phosphoglyceric acid and thus no inorganic phosphate is sat free during the lactic acid pro. duction.

It is very interesting that monoiodoacetic acid, which also inhibits the splitting of carbohydrates, affects the reaction at an entirely different point. In muscle extract poisoned with iodoacetic acid 
the splitting off of the phosphate of phosphoglyceric acid and the consequent formation of pyruvic acid proceed undisturbed. The pyruvic acid cannot, however, react with the glycerophosphoric acid, so that here no lactic acid formation takes place.

These results could also be explained in another way. The triose phosphoric acid appearing as an intermediate during the reaction between pyruvic acid and glycero-phosphoric acid might itself be resynthesised to hexose di-phosphoric acid which then decomposes into an oxidised and a reduced half. This interpretation, that the splitting of the carbon-carbon bond at the $3: 4$ position is at the same time an oxidation-reduction process, certainly has its merits. However, the behaviour of glyceric aldehyde phosphoric acid lends support to the supposition of a previous decomposition to triose phosphoric acid. H. O. L. Fischer, the son of Emil Fischer, succeeded not long ago in synthesising glyceric aldehyde phosphoric acid. Smythe and Gerischer, working in $O$. Warburg's institute, showed that the dextro-rotary component of this racemic compound is easily fermented and Embden has observed abundant formation of lactic acid on addition of glyceric aldehyde phosphoric acid to muscle tissue.

Thanks to the courtesy of Dr. Fischer, I was able to study the appearance of intermediate products in muscle extract during the reactions of this substance. Actually, exactly one half, that is one optical component, was transformed into phosphoglyceric acid and glycero-phosphoric acid. In the muscle extract with added sulphite, but without fluoride, pyruvic acid and glycero-phosphoric acid were formed. The glyceric aldehyde phosphoric acid thus behaves exactly as does the intermediary product. 'This is thus the first synthetic ester that is converted into lactic acid as easily and by the same path as the biological esters.

${ }^{1}$ Biochem. Z., 222, 337, Fig. 8; 1930.

(To be continued.)

\section{Ionospheric Investigations in High Latitudes}

\section{By Prof. E. V. Appleton, F.R.S., R. Naismitir and G. Bullder}

$\mathrm{I}^{\mathrm{N}}$ connexion with the International Polar Year 1932-33, a series of wireless observations has been made at Tromsø (lat. $69^{\circ} 39 \cdot 8^{\prime} \mathrm{N}$. ; long. $18^{\circ} 56 \cdot 9^{\prime}$ E.) in Norway. The fundamental aim of the work may be briefly stated to be the investigation of ionospheric conditions in high latitudes and of the relation between these conditions and magnetic and auroral disturbance. The observations may be regarded as an extension of the work previously conducted on similar lines in south-east England by British workers under the auspices of the Radio Research Board of the Department of Scientific and Industrial Research. The expedition to Norway for the thirteen months of the International Polar Year has been sent out by that Department and contributions towards the total cost have been made by the British National Committee for the Second Polar Year and by the Council of the Institution of Electrical Engineers.

Special facilities and privileges have been accorded to the expedition by the Norwegian Government and by the Norwegian Committee for Cosmic Physics, while the latter body invited us to make our principal receiving station at the Auroral Observatory, Trcmsø, where laboratory and living accommodation has been provided. The sending station was erected at Simavik, about $20 \mathrm{~km}$. north of Tromsø, on the island of Ringvassøy. The choice of these sites and many other helpful arrangements were made for us by Mr. R. A. Watson Watt, who visited Tromsø in March, 1932. It has proved a great advantage to have the receiving site at the Observatory at Tromsø, where the magnetic records have been immediately available and where Director Harang and Mr.E.Tønsberg have given us every other possible assistance. A member of our party, Mr. W. C. Brown, has been in charge of the sending station at Simavik during the whole period of the observations.

The expedition arrived in Tromsø on July 15, 1932 , and the sending and recciving stations were erected and in working order by July 22 . Observations according to the programme prepared by the Polar Year Sub-Committee of the Union Radio Scientifique Internationale and in accordance with a special British programme have been carried out since the beginning of August 1932, while corresponding measurements for purposes of comparison have been made in south-east England. A full account of the results obtained must naturally await the completion of the remainder of the series of observations and the full reduction of the data; but since the beginning of the work certain results have been immediately apparent and their continued confirmation prompts this interim statement.

Before proceeding to summarise some of the salient results obtained, it may perhaps be useful to mention the kind of problem which it was hoped would be solved by a comparison of ionospheric measurements in high and temperate latitudes. If ultra-violet light is the ionising agency for either of the two main reflecting regions in the upper atmosphere, we should expect that region to be more strongly ionised by day than by night, and also to be of lower electrical content at Tromsø than in south-east England. On the other hand, if charged particles, entering the earth's atmosphere from outside, constitute the ionising agency, the influence of the earth's magnetic field is such that these particles should be expected to converge near the magnetic poles and also to impinge on the dark side of the earth. In this case it will readily be seen that their effects should be radically different from those produced by ultra-violet 